\title{
Application of bioactive compounds for increasing production of grape planting materials and higher germination of hybrid seeds
}

\author{
Olga Seget $^{1}$, Irina Avdeenko², Galina Aleynikova ${ }^{1}$, and Grigori Malih² \\ ${ }^{1}$ Federal State Budget Scientific Institution «North Caucasian Federal Scientific Center of Horticulture, \\ Viticulture, Wine-making», 39 str. 40 Let Pobedy, Krasnodar, 350901, Russia \\ ${ }^{2}$ All-Russian Research Institute named after Ya.I. Potapenko for Viticulture and Winemaking - Branch of \\ "Federal Rostov Agricultural Research Center", 166 ave. Baklanovsky, Novocherkassk, 346421, Russia
}

\begin{abstract}
The paper presents the results of studying biological methods of increasing the yield of planting material for grapes and increasing the germination of hybrid seeds to accelerate the selection process. The impact of bioactive compounds (6-benzylaminopurine and gibberellic acid) in culture medium on production of grape clones during micropropagation stage was studied. Modified culture medium of the A.N. Rebrov's patent was determined as having_the most potential on the first stage of grape explant cultivation. The establishment of grape regenerant plants was up to $80 \%$, depending on the variety. On the second and third passages Rebrov's culture medium was modified by the addition of 6-benzylaminopurine in the concentration $0.35 \mathrm{mg} / \mathrm{l}$ and gibberellic acid in the concentration $0.1 \mathrm{mg} / \mathrm{l}$. The method of prestratification soaking of seedlings seeds in the solutions of gibberellic acid of various concentrations was also studied to accelerate the breeding process. The production of seedlings increased to $91.2 \%$ at the concentration of gibberellic acid $0.01 \%$ that was higher than control production on $31.2 \%$.
\end{abstract}

\section{Introduction}

Nowadays the development of viticulture is one of the priority areas in the system of developing plans and programs for strategic planning of industry in the Russian Federation. [1]. In Russia, the establishment of new vineyards is carried out by both domestic and imported planting material. The domestic nursery base allows to provide only $20-25 \%$ of the need for grafted seedlings [2]. However, imported varieties are often not adapted to the soil and climatic conditions of the wine-growing regions of the Russian Federation, and are often of low quality. [3]. Cultivation of high-priced local breeding grape varieties with increased resistance ability to diseases, phylloxera and frosts shall help to increase the production of grape, stability of ampelocenosis and significantly reduce the pesticide burden on the environment [4]. The intensification of viticulture determines the need to develop new effective technologies, directions and methods, their inclusion in the production system of healthy planting material [5]. The low reproduction rate is the main deterrent to the process of introducing a new variety into production using traditional methods, due to the inability to obtain a large amount of grape planting material in one season [6]. One of the available ways to increase the reproduction rate is the use of modern 
advances in biotechnology, namely, micropropagation of grapes [7, 8]. The application of bioactive compounds in pre-stratification soaking of grape seeds can be used to increase the germination of hybrid seeds and accelerating the process of breeding new grape varieties, consequentially $[9,10]$. There are some challenges for the application of the micropropagation technique in the industrial scale $[11,12]$. Each plant object introduced into in vitro culture requires an individual approach and careful selection of the composition of an artificial nutrient medium, taking into account its genotypic characteristics.

$[13,14,15]$. Thus, the study of ways to optimize the nutrient medium to increase the multiplication factor in vitro and, accordingly, increase the efficiency of the process of obtaining a healthy planting material for grapes is a very relevant area of research.

The purpose of the research is to study biological methods for increasing the production of grape planting material during in vitro reproduction by modifying nutrient medium and the method for increasing the production of seedlings to accelerate the breeding process.

\section{Materials and Methods}

Study objects in the first experiment of selecting optimized culture medium for introduction to in vitro culture were grape varieties (Krasnostop AZOS, Avgustin, Aligote, Kishmish 342, Riesling, Granatovy, Chasla x Berlandieri 41 B, Berlandieri $\times$ Riparia CO4, Ruggeri 140, Moldova, Barkhatny, Cabernet Sauvignon, Attica, Berlandieri x Riparia Kober 5BB, AZOS - 4), mineral and hormonal salts composition of medium, stimulators and growth regulators (BAP and GA3).

In the second experiment the objects of study were hybrid grape seeds and regulations for prestratification soaking of seeds.

Experimental design № 1. Selecting optimized culture medium for introduction to in vitro culture, 90 explants each:

1. Control-modified MS culture medium;

2. $\mathrm{M}_{1}$ culture medium by N.I. Medvedeva;

3. A.N. Rebrov's modified culture medium.

Methodology of the study in the first experiment. The experiment of micropropagation was conducted by universally accepted methods in the laboratory conditions of the FSBSI NCFSCHVW. As a sterilizing agent, OKA-TAB disinfecting tablets containing 50\% active chlorine were used (treatment with $0.5 \%$ solution for 5 minutes with 3 times washing with distilled water). In order to improve grape varieties, explants with a size of $0.3-0.5 \mathrm{~mm}$ were used. At the first stage of introducing the grape apical meristems to in vitro culture following culture medium were used: Murashige and Skoog (MS), $\mathrm{M}_{1}$ by N.I. Medvedeva and modified culture medium by A.N. Rebrov.

Experimental design № 2. Pre-stratification soaking of hybrid seeds, 100 units each:

1. Control - pre-stratification soaking of seeds in the solution with the $3 \%$ concentration of $\mathrm{Na}_{2} \mathrm{CO}_{3}$;

2. Pre-stratification soaking of seeds in the solution with the $0.01 \%$ concentration of gibberellic acid;

3. Pre-stratification soaking of seeds in the solution with the $0.03 \%$ concentration of gibberellic acid;

4. Pre-stratification soaking of seeds in the solution with the $0.04 \%$ concentration of gibberellic acid.

Methodology of the study in the second experiment. Hybrid grape seeds were soaked in warm water at the temperature of $20-25^{\circ} \mathrm{C}$ in the middle of December. After the first soaking of the seeds and its saturation with moisture, repeated soaking was conducted in gibberellic acid solutions according to the experiment design № 2 (duration: 24 hours).

The seeds were sown after a second soaking in gibberellic acid in pots with a substrate to a depth of 5-6 cm and substrate was irrigated; after that, the pots were placed in a stratification 
chamber maintaining optimal humidity conditions at $85-90 \%$ and a temperature of $25-27^{\circ} \mathrm{C}$ until achieving an increase of $60 \mathrm{~cm}$ in growth.

\section{Results and Discussion}

In the process of the experiment it was found that on the first stage of grape clones regeneration the best possible medium for most varieties was modified culture medium by A.N. Rebrov (fig. 1). Explant survival of following varieties: Krasnostop AZOS, Berlandieri $\times$ Riparia CO4, Ruggeri 140 was $100 \%$. It is necessary to notice specify of varieties: for Attica variety the best culture medium was MS, for Cabernet Sauvignon - $\mathrm{M}_{1}$.

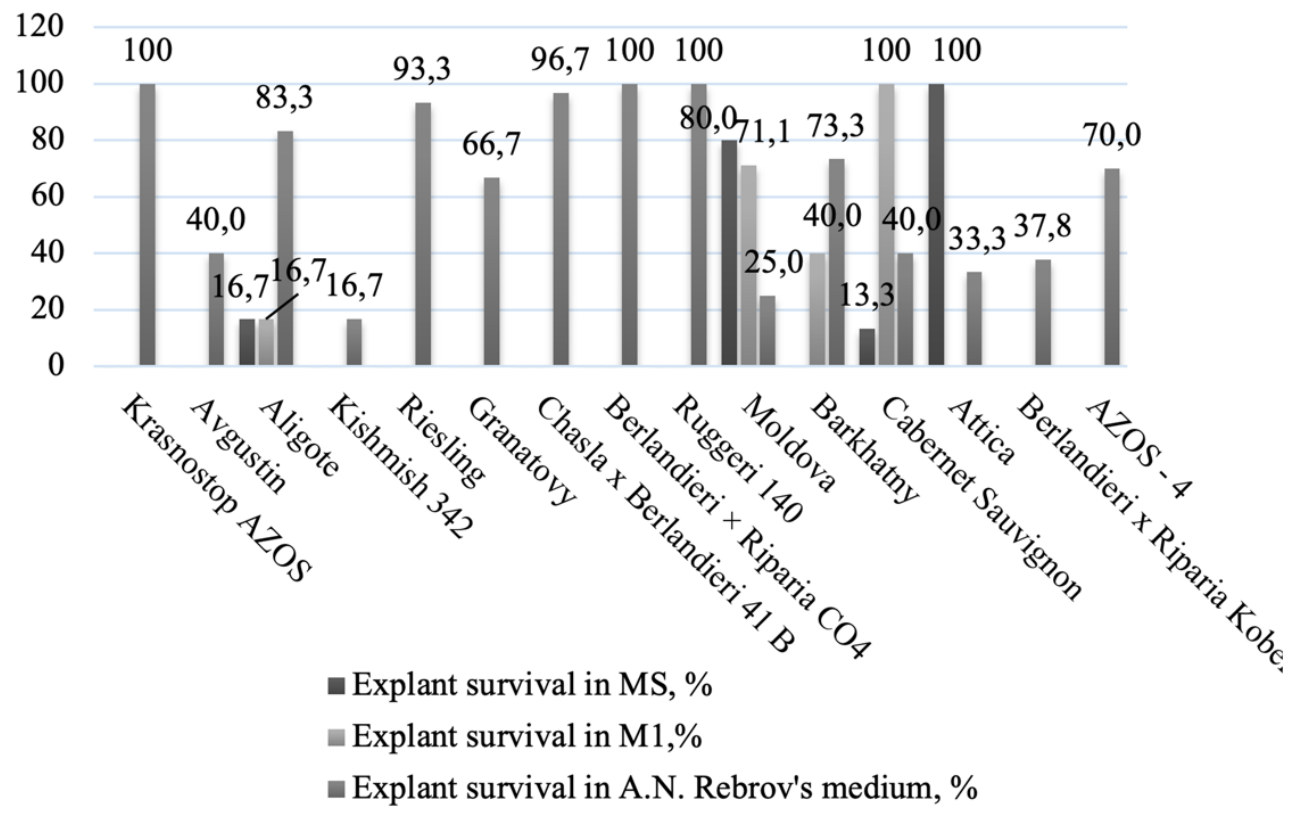

Fig. 1. The survival rate of explants of grape varieties in different culture medium, $\%$

A month after planting, the established meristems developed into cluster-shoots $2 \ldots 4 \mathrm{~mm}$ in size, which were transplanted onto a nutrient medium containing the same components according to the modified recipe of A.N. Rebrov's patent. At the stage of introducing explants, their survival on the modified culture medium according to the A.N. Rebrov patent was quite high: $80.0 \%$ Attica variety; $68.9 \%$ in the variety of Shasla $\times$ Berlandieri $41 \mathrm{~B}, 66.6 \%$ in the variety of Ruggieri 140 (Fig. 2).

Cabernet Sauvignon variety was the exception - the percentage of infected shoots was highest possible (100\%). Within 20-35 days, regenerants of plants 4-6 cm in size were formed. After that micropropagation was carried out. The obtained microshoots were introduced in tubes measuring $30 \times 100 \mathrm{~mm}$. The tubes were transferred to a culture room with optimal conditions for the growth and development of grape clones. Currently, microshoots are in the cultivation stage. 


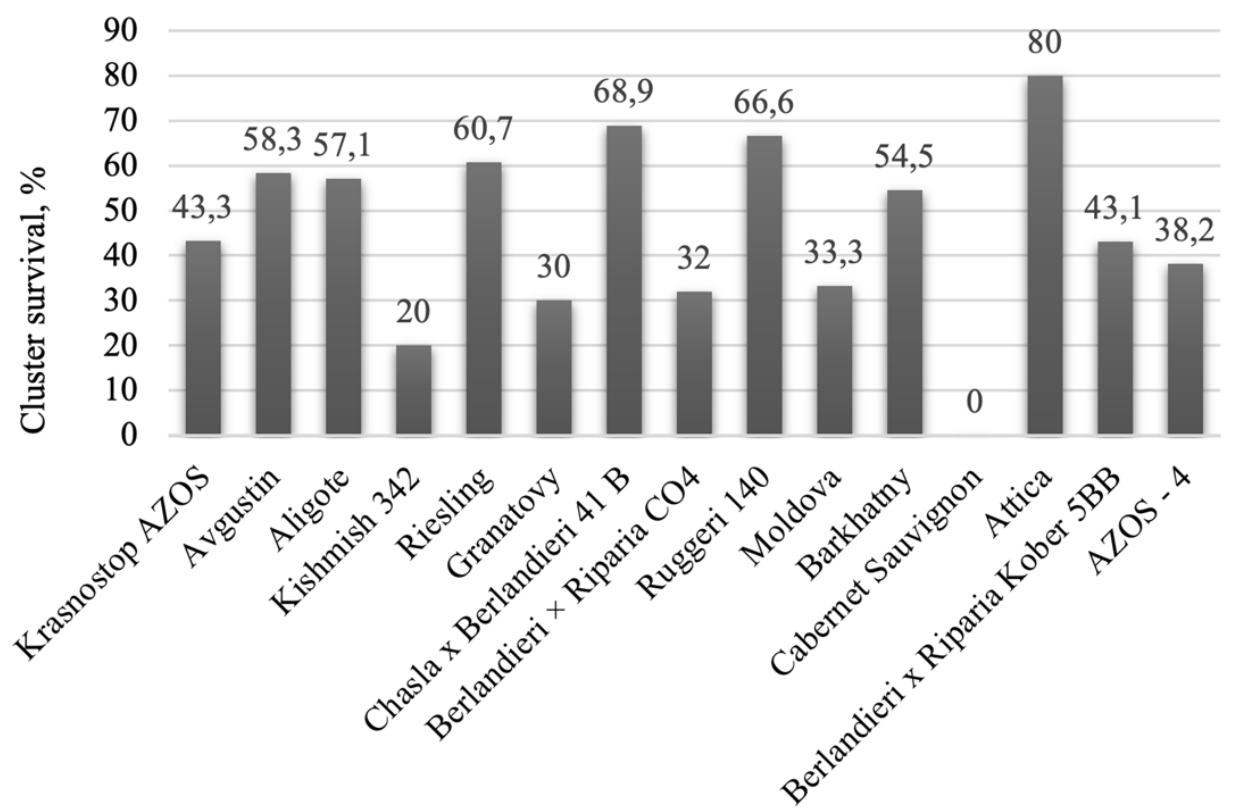

a Cluster survival, \%

Fig. 2. The survival rate of cluster-shoots of grape varieties on a modified nutrient medium according to the patent of A.N. Rebrov.

In addition, we studied the effect of the concentration of gibberellic acid in solutions for prestratification soaking of grape seeds in purpose to increase the production of seedlings and accelerate the breeding process. It was found that the application of gibberellic acid in soaking seeds has a significant effect on the production of seedlings at a concentration of 0.01 to $0.04 \%$ (Fig. 3). When the seeds were soaking before stratification according to the conventional technology in a 3\% solution of sodium sulfite, the production of seedlings was $60 \%$ (control). gibberellic acid has been applied before stratification of grape seeds, there was a significant increase in the production of seedlings to $91.2 \%$, which is $9.5-31.2 \%$ higher than the control. Differences in production percentage depended on the concentration of gibberellic acid. It was found that increasing the concentration from 0.01 to $0.04 \%$ reduces the growth-stimulating effect, and decreases the percentage of production of seedlings from 91.2 to $69.5 \%$. 


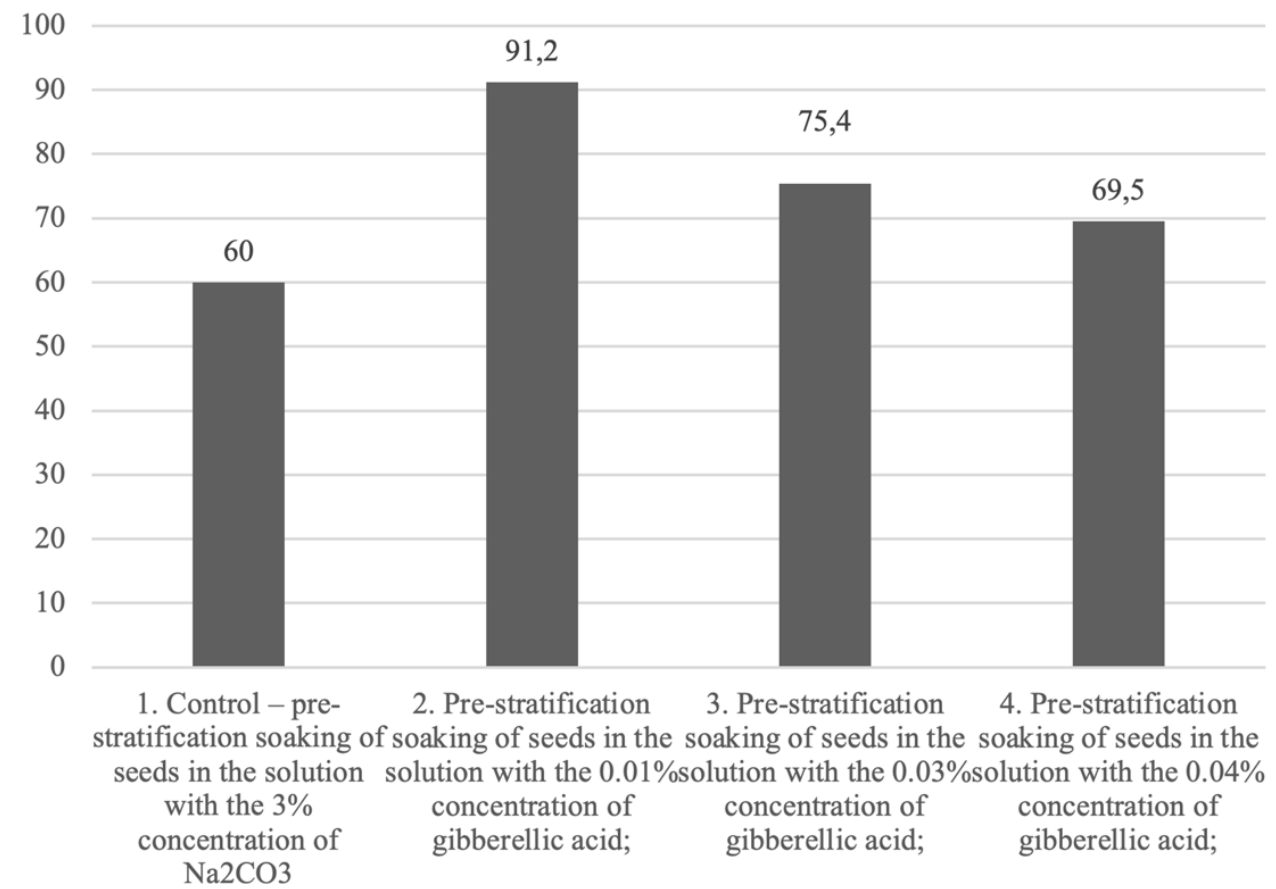

Fig. 3. The seedling production after soaking hybrid grape seeds.

The application of gibberellic acid for pre-stratification soaking of grape seeds has influence on the morphological development of seedlings (Fig. 4).

200

0

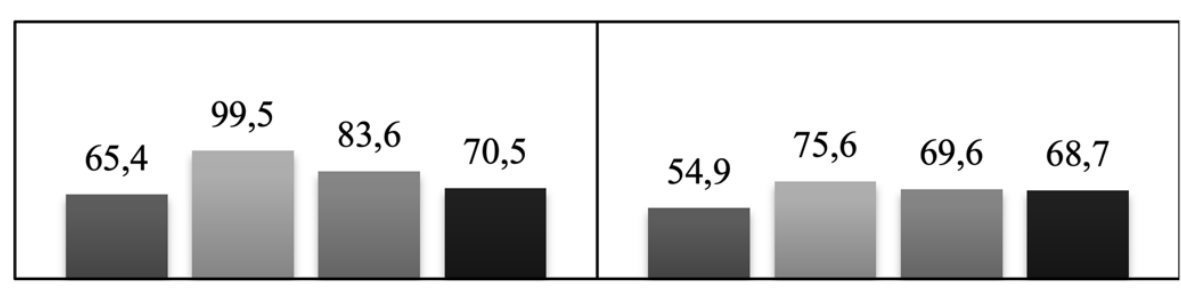

Average increase of shoot, $\mathrm{cm}$

Leaf-area duration, $\mathrm{cm} 2$

1. Control - pre-stratification soaking of seeds in the solution with the $3 \%$ concentration of $\mathrm{Na} 2 \mathrm{CO} 3$

Fig. 4. Indicators of morphological development of hybrid seedlings in the first year of life (May).

In the control variant, the average increase of shoots in seedlings was $65.4 \mathrm{~cm}$, and the average leaf-area duration was $54.9 \mathrm{~cm}^{2}$. The average increase of shoot was $34.1 \mathrm{~cm}$ greater than the control from using a minimum concentration of gibberellic acid $(0.01 \%)$. The average leaf-area duration increased by $20.7 \mathrm{~cm}^{2}$ to $75.6 \mathrm{~cm}^{2}$ in this case. Significant differences between the concentrations of 0.03 and $0.04 \%$ were observed only for the average increase of shoot $(13.1 \mathrm{~cm})$, no significant difference was found in the leaf-area duration.

\section{Conclusion}

It was found that the majority of grape varieties the best culture medium for the survival of explants was modified nutrient medium by A.N. Rebrov with a gibberellic acid content of $0.1 \mathrm{mg} / \mathrm{l}$. Soaking 
the seeds until stratification in a $0.01 \%$ solution of gibberellic acid also showed a significant increase in the production of seedlings and the influence on their morphological development. Consequently, the application of gibberellic acid in viticulture is effective due to the high responsiveness of the seeds and explants of grapes to its use. This will increase the effectiveness of the grape micropropagation and increase the germination of hybrid grape seeds to accelerate the breeding process.

\section{References}

1. R. Hall, N. Penke, M. Kriechbaum et. al., Agric Syst, 177, 102706 (2020). https://doi.org/10.1016/j.agsy.2019.102706

2. M. Pingel, A. Reineke, I. Leyer, Agric Ecosyst \& Environ, 272, 114-125 (2019). https://doi.org/10.1016/j.agee.2018.11.005

3. T. Dzhambazova, I. Tsvetkov, I. Atanassov et. al, J INT SCI VIGNE VIN, 2, 113-121 https://doi.org/10.20870/oeno-one.2012.46.2.1510

4. S. Sabbadini, L. Capriotti, C. Limera et. al., BIO Web Conf., 12, 01019 (2019). https://doi.org/10.1051/bioconf/20191201019

5. F. Altindisli, BIO Web Conf., 3, 01009 (2014). https://doi.org/10.1051/bioconf/20140301009

6. L. Oganesyants, A. Panasyuk, H. Kuzmina, BIO Web Conf., 5, 02018 (2015). https://doi.org/10.1051/bioconf/20150502018

7. M. Jina, X. Piaoa, J. Xiub et. al, Sci Hortic, 164, 35-40 (2013). https://doi.org/10.1016/j.scienta.2013.09.004

8. M. Maçanita, R. Santos, C. Gomes, Aust J Grape Wine R, 4, 450-460 (2018). https://doi.org/10.1111/ajgw.12353

9. P. Pertuzattia, S. Mendonça, M. Alcoléa et. al., 129, 109625 (2020). https://doi.org/10.1016/j.lwt.2020.109625

10. S. Ali, H. Kucukbasmaci, Sci Hortic, 272, 109589 (2020). https://doi.org/10.1016/j.scienta.2020.109589

11. A. Batukaev, M. Mukailov, M. Batukayev, T. Minkina, S. Sushkova, International $\begin{array}{llllll}\text { multidisciplinary scientific } & \text { geoconference } & \text { SGEM, 62, } & 783-790 & \text { (2018). }\end{array}$ https://doi.org/10.5593/sgem2018/6.2/S25.103

12. F. Vera-Sirera, M. Dolores-Gomez, M.A. Perez-Amador, Plant TF, 20, 313-328 (2016). https://doi.org/10.1016/B978-0-12-800854-6.00020-8

13. P. Read, J. Preece, Encyclopedia of Agriculture and Food Systems, 317-336 (2014). https://doi.org/10.1016/B978-0-444-52512-3.00224-2

14. Z. Han, G. Liu, Q. Rao et. all, J Chromatogr B, 881, 83-89 (2012). https://doi.org/10.1016/j.jchromb.2011.12.002

15. A. Batukaev, I. Bamatov, E. Khadzhimuradova, J Pharm Sci \& Res, 10(1), 106-109 (2018). https://www.researchgate.net/publication/322939779 